\begin{tabular}{|l|l|l|}
\hline Received: Maret 2019 & Accepted: April 2019 & Published : April 2019 \\
\hline
\end{tabular}

\title{
Digital Tone Control Menggunakan Mikrokontroller 8-bit
}

\author{
Turahyo ${ }^{1^{*}}$ \\ $1^{1^{*}}$ Sekolah Tinggi Teknologi Bontang, \\ Jl. Ir. Juanda No. 73 Rawa Indah, Bontang \\ E-mail: turahyoahyo@gmail.com
}

\begin{abstract}
The quality of the audio sound system that is generated depends on the tone control. Good audio tone control signal output produces an audio signal that approaches the input audio signal. Tone controls are generally used on audio sound system devices using potentiometers as regulating devices. Potentiometers are done in charcoal powder which has varying and linear barriers. Problems that often arise in potentiometers in the form of quick wear due to frequent friction, the output of the tone control will produce a noise when the relationship between the powder charcoal and the sweeping lever is not well connected, and linearity will change if the potentiometer is dirty due to dust. Microcontroller is electronic equipment that can be programmed according to user need. With a collaboration push button, Multiplexer and Analog to digital converter (ADC), can be utilized instead of a potentiometer. Setting the potentiometer is done by pressing the digital control tune up / down button. Based on the testing of the tone control on the volume setting, the input signal has strengthened $6.02 \mathrm{~dB}$. In the bass setting, a signal with a frequency of 100-1 khz is passed, while the frequency of $2.5 \mathrm{khz}$ is muted. In the treble setting, the frequency passed is $2.5 \mathrm{khz}$ to $16 \mathrm{khz}$.
\end{abstract}

Keywords: Digital Tone Control, Microcontroller, Multiplexer.

\begin{abstract}
Abstrak
Baik buruknya kualitas audio sound system yang dihasilkan tergantung pada tone control. Keluaran sinyal audio tone control yang baik menghasilkan sinyal audio yang mendekati sinyal audio masukannya. Tone control pada umumnya dipakai pada perangkat audio sound system menggunakan potensiometer sebagai perangkat pengatur. Potensiometer terbuat dari serbuk arang yang mempunyai hambatan yang bervariasi dan linier. Permasalahan yang seringkali timbul pada potensiometer berupa cepat aus karena sering terjadi gesekan, keluaran tone control akan menghasilkan noise apabila hubungan antara serbuk arang dengan tuas penyapunya tidak terhubung dengan baik, dan linieritas akan berubah apabila potensiometer kotor karena debu. Mikrokontroller merupakan peralatan elektronik yang dapat diprogram sesuai dengan kebutuhan pengguna. Dengan kolaborasi push button, Multiplexer dan Analog to digital converter (ADC), dapat digunakan sebagai pengganti potensiometer. Pengaturan potensiometer dilakukan dengan menekan tombol up/down tone control digital. Berdasarkan pengujian tone control pada pengaturan volume, sinyal masukan mengalami penguatan 6,02 dB . Pada pengaturan bass, sinyal dengan frekuensi 100-1 khz diloloskan, sedang frekuensi $2,5 \mathrm{khz}$ diredam. Selain itu pada pengaturan treble, frekuensi yang diloloskan sebesar $2,5 \mathrm{khz}$ sampai $16 \mathrm{khz}$.
\end{abstract}

Kata kunci: Digital Tone Control, Mikrokontroller, Multiplexer. 


\section{PENDAHULUAN}

Dalam sound system baik buruknya kualitas suara yang dihasilkan tergantung pada tone control. Bentuk sinyal audio yang mendekati sinyal asli audio masukan ( hi-fi) serta amplitudo sinyal audio keluaran yang lebih besar dari sinyal audio masukan, merupakan salah satu ciri tone control yang mempunyai kualitas baik [1]. Dalam sistem audio, frekuensi dari tone control harus disesuaikan dengan tanggapan frekuensi dari loadspeaker dan pendengaran manusia [2]. Beberapa desain tone control yang sering dipakai adalah tone control Baxandall.

Desain ini menggunakan umpan balik negatif yang digunakan untuk menghasilkan suara yang mendekati hi-fi. Dengan pengaturan tone cut flat boost (potong-datar dan diperkuat) pada dua tanggapan frekuensi yaitu bass (frekuensi bawah) dan treble (frekuensi atas). Pengaturan nada bass dan treble dilakukan secara terpisah yaitu dengan sebuah pengatur nada bass dan sebuah lagi pengatur nada treble. Hal ini dilakukan untuk mempermudah dalam pengaturan sinyal frekuensi keluaran pada tone control[3-4].

\section{METODOLOGI}

\section{Arsitektur Tone Control Digital}

Untuk mempermudah perancangan sistem audio tone control digital, maka perancangan dibagi untuk tiap-tiap blok dengan urutan dari blok masukan dilanjutkan dengan blok pemroses sinyal sampai dengan blok keluaran sinyal.

Pada penelitian ini tone control yang digunakan adalah tone control mono dengan sebuah penguat. Selain itu, filter yang digunakan adalah filter $\mathrm{RC}$ aktif menggunakan penguat operational amplifier (OP-AMP). Tombol volume, bass, dan treble merupakan tombol pengaturan up/down / naik-turun sinyal pada tone control digital, seperti yang diperlihatkan pada gambar 1 .

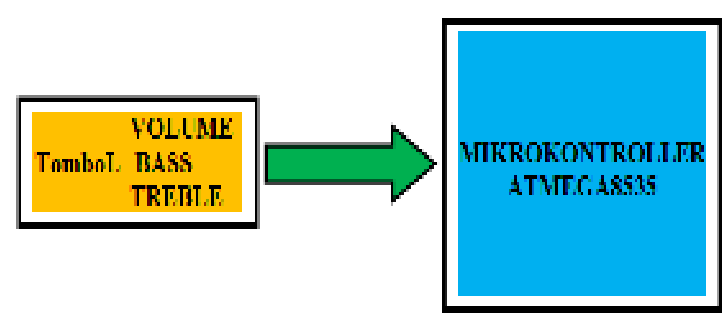

Gambar 1. Diagram blok tone control digital.

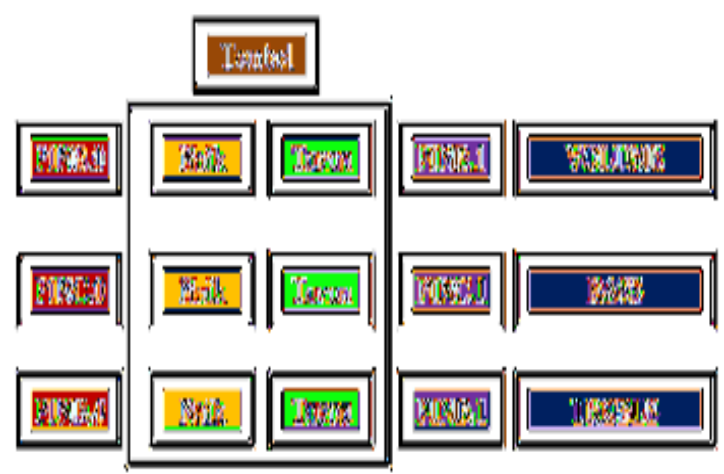

Gambar 2. Diagram blok tombol up/down pada mikrokontroller.

Pada gambar 2 diperlihatkan tombol pengontrol volume naik pada tone control di hubungkan pada PINB.0 Mikrokontroller Atmega8535 sedangkan tombol pengontrol volume turun dihubungkan pada PINB.1. Pada pengaturan bass tombol naik-turun dihubungkan dengan Mikrokontroller pada PORTC.0 dan PORTC.1. PINC.0 merupakan tombol kontrol bass naik sedangkan untuk tombol turunnya dihubungkan pada PINC.1. Pada tombol pengaturan treble, PORT mikrokontroller yang digunakan adalah PORTD.Tombol pengaturan treble naik dihubungkan pada PIND.0 dan tombol pengaturan treble turun dihubungkan dengan PIND.1.

\subsection{Tone Control Aktif}

Pada penelitian ini tone control yang digunakan adalah tone control aktif . Dalam tone control ini, sebagian sinyal keluarannya akan kembali menjadi sinyal masukan atau yang lebih dikenal dengan istilah umpan balik. Proses tersebut akan memperbaiki kualitas sinyal keluaran dari tone control 
tersebut. Dalam pengaturan frekuensi yang diloloskan, tone control menggunakan dua buah kapasitor sebagai filter frekuensi tinggi dan frekuensi rendah dari sinyal masukan. Beberapa tahanan digunakan sebagai umpan balik negatif tone control. Pada penelitian ini IC OP_AMP yang digunakan adalah IC LM 741 yang mempunyai 8 buah pin [5]. Rangkaian penguat tone control aktif diperlihatkan pada gambar 3 .

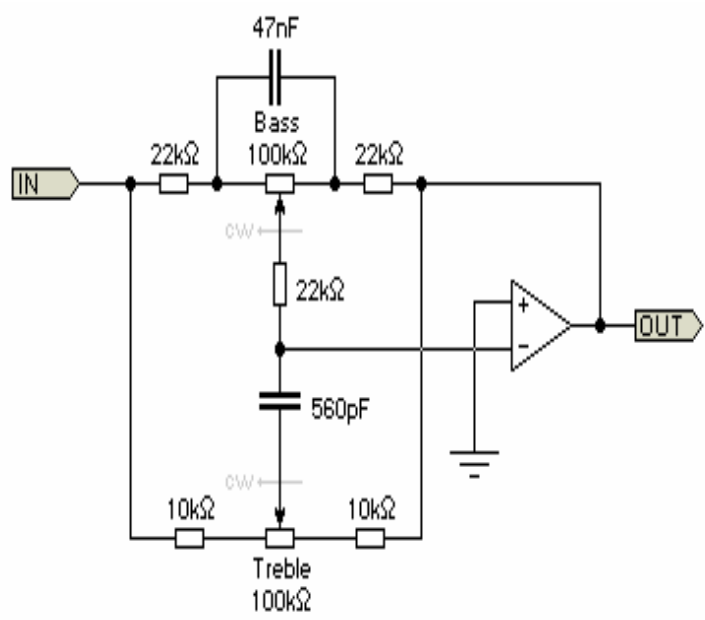

Gambar 3. Rangkaian penguat tone control aktif.

\section{Multiplexer dan Decoder}

Mikrokontroller Atmega8535 sebagai pusat kendali dari perangkat ini tidak dapat bekerja secara langsung mengontrol langkahlangkah pengaturan tombol naik-turun dari pengaturan volume, bass dan treble. Oleh sebab itu dibutuhkan perangkat yang mampu menjembatani pengaturan volume, bass dan treble pada tone control. Peragkat tersebut adalah Multiplexer dan decoder. Perangkat ini difungsikan sebagai pengganti langkahlangkah kerja potensiometer. Rangkaian pengatur volume dan bass diperlihatkan pada gambar 4 dan 5, sedangkan gambar 6 memperlihatkan rangkaian pengatur treble.

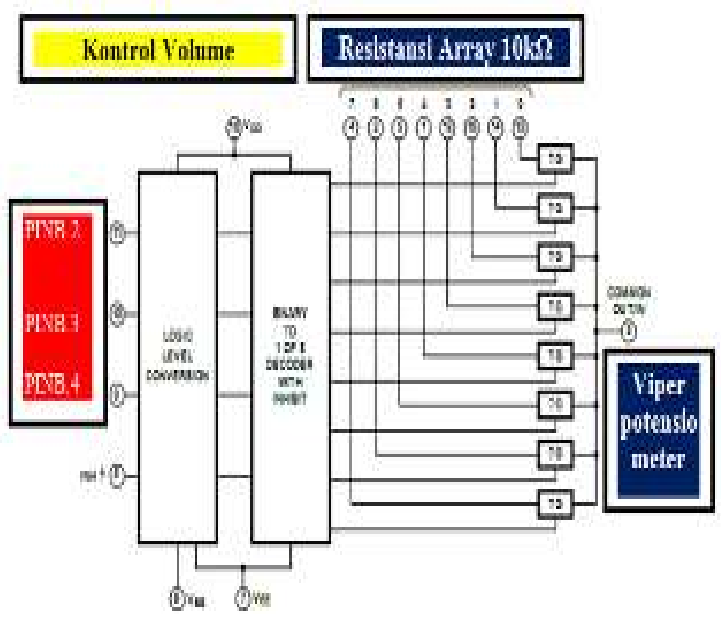

Gambar 4. Rangkaian pengatur volume.

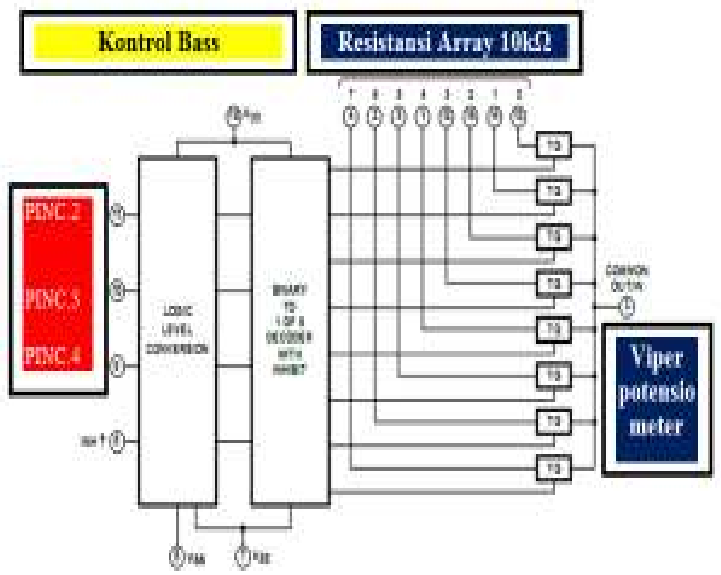

Gambar 5. Rangkaian pengatur bass.

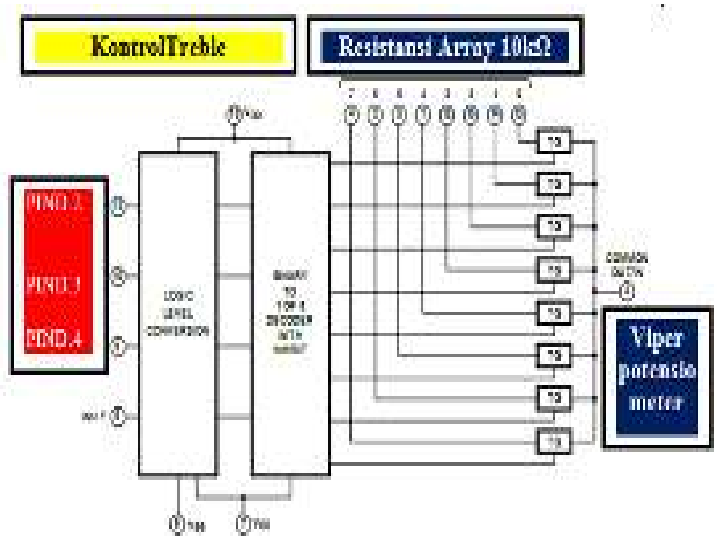

Gambar 6. Rangkaian pengatur treble. 


\section{Liquid Cristal Display (LCD)}

Karena tampilannya menarik, LCD banyak digunakan sebagai display. LCD yang paling banyak digunakan saat ini ialah LCD M1632 refurbish karena harganya cukup murah. LCD M1632 merupakan modul LCD dengan tampilan 2x16 yang artinya terdiri dari 2 baris dan 16 kolom dengan konsumsi daya cukup rendah. Modul LCD tersebut dilengkapi dengan mikrokontroler yang didesain khusus untuk mengendalikan LCD dengan baik. Gambar 7 memperlihatkan susunan alamat pengaturan pada LCD 2x16.

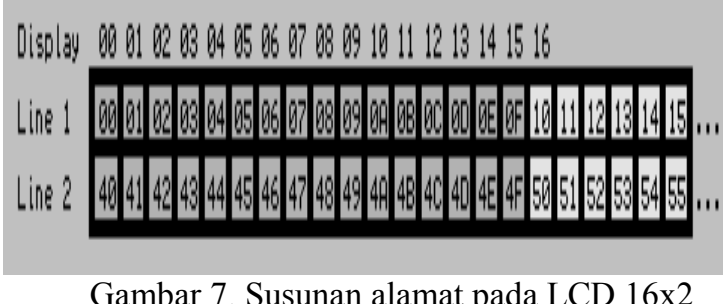

Alamat awal karakter adalah $00 \mathrm{H}$ dan alamat akhirnya $39 \mathrm{H}$. Pada alamat awal di baris kedua dimulai dari $40 \mathrm{H}$. Apabila menginginkan meletakkan suatu karakter pada baris ke-2 kolom pertama, maka alamat LCD harus diset pada alamat $40 \mathrm{H}$. Gambar 8 menunjukan rangkaian pengendali LCD pada mikrokontroller.

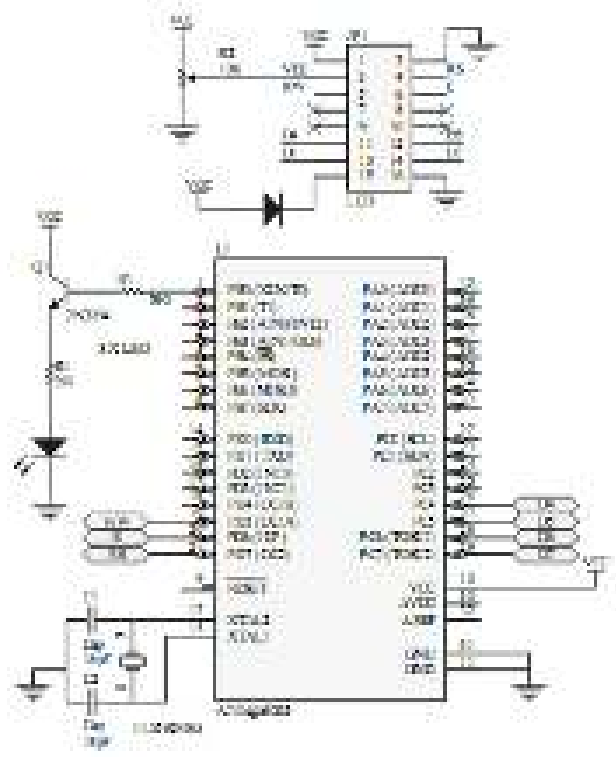

Gambar 8. Rangkain LCD pada Mikrokontroller

\section{HASIL DAN PEMBAHASAN \\ Tombol Up/Down Mikrokontroller}

Setelah dilakukan pengujian secara implisit didapatkan hasil bahwa ke-6 tombol up/down yang digunakan sebagai pengaturan volume, bass, dan treble berfungsi dengan baik sesuai dengan yang direncanakan. Peralihan kenaikan dan penurunan pada pengaturan volume, bass, dan treble tidak menimbulkan sinyal noise yang biasa terjadi bila menggunakan clock frekuensi tinggi. Pada pengaturan sinyal kontrol langkah, dari langkah ke-0 sampai langkah ke-7 dapat berfungsi dengan baik tanpa terjadi lompatan langkah atau dapat dikatakan berurutan.

\section{Pengaturan Sinyal Pada Volume}

Dalam pengujian ini tone control diberikan sinyal sinus masukan pada tegangan $100 \mathrm{mV}$ dengan frekuensi $100 \mathrm{~Hz}, 1 \mathrm{kHz}$, dan $16 \mathrm{kHz}$. Sebelum merubah langkah pengaturan, langkah pengaturan bass dan treble dikondisikan pada posisi flat atau $0 \mathrm{~dB}$ yaitu pada langkah pengaturan 3. Setelah dilakukan perubahan pengaturan langkah dari langkah ke-0 sampai langkah ke-7 didapatkan hasil penguatan sinyal masukan sebesar 6,02 $\mathrm{dB}$ sedangkan tegangan setiap langkah pengaturan diperlihatkan pada tabel 1. Pada tabel 1 ini tegangan dalam skala $\mathrm{mV}$.

Tabel 1. Tegangan pengaturan Volume

\begin{tabular}{|c|c|c|c|c|c|c|c|c|}
\hline Proms & $\begin{array}{c}14 x+4 k \\
4 \times k\end{array}$ & $\begin{array}{c}\text { akeat: } \\
\text { col }\end{array}$ & 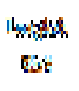 & 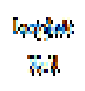 & 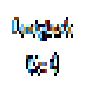 & 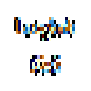 & 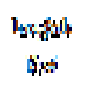 & wopht \\
\hline 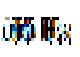 & 僬 & 鳃 & $4 \mathrm{x}$ & $M N$ & $x_{3}$ & $M$ & 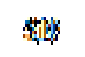 & 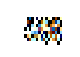 \\
\hline ل放 & $*$ & 楼 & 39 & 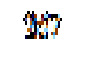 & 懒 & 56 & 㱐 & $82 y$ \\
\hline 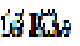 & 新 & 消能 & thes & 35 & 4 & $b 0$ & 的 & 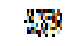 \\
\hline
\end{tabular}

\section{Pengaturan Sinyal Pada Bass}

Sinyal masukan berupa gelombang sinus dengan tegangan $100 \mathrm{mV}$ dilakukan pada pengujian ini. Frekuensi sebesar $100 \mathrm{~Hz}, 500$ $\mathrm{Hz}, 1 \mathrm{kHz}, 5 \mathrm{kHz}$, dan $16 \mathrm{kHz}$ di gunakan dalam pengaturan langkah ini. Pada pengaturan awal sebelum dilakukan pengaturan langkah bass, pengaturan langkah 3 atau $0 \mathrm{~dB}$ dilakukan pada pengaturan volume dan treble. Setelah dilakukan pengaturan langkah ke-0 sampai langkah ke -7 didapatkan 
hasil tegangan tertinggi sebesar $440 \mathrm{mV}$ pada frekuensi $100 \mathrm{~Hz}$ sedangkan tegangan terendah di dapatkan pada frekuensi $16 \mathrm{kHz}$ dengan tegangan sebesar $25 \mathrm{mV}$. Tegangan setiap langkah pada pengaturan bass diperlihatkan pada tabel 2. Pada tabel 2 ini tegangan dalam skala $\mathrm{mV}$.

Tabel 2. Tegangan pengaturan bass.

\begin{tabular}{|c|c|c|c|c|c|c|c|c|}
\hline 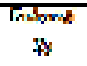 & 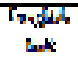 & $\begin{array}{c}6.1 \times 1 \\
6.1\end{array}$ & 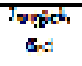 & $\begin{array}{c}4+456 \\
6-4\end{array}$ & 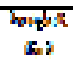 & $\begin{array}{c}i_{i=6} b h \\
8+4\end{array}$ & $\begin{array}{c}\operatorname{condd} \\
r d\end{array}$ & $\begin{array}{l}\text { Werm } \\
\text { Whi }\end{array}$ \\
\hline $\cos \mathrm{k}$ & $\theta_{1}$ & 208 & $3 \pi$ & Sh & as? & Isel & $2, \sqrt{6}$ & $\$ \infty$ \\
\hline selis & $b \rightarrow$ & Ts4 & $w$ & X3 & 绡 & s. & idy & Pil \\
\hline $1 \mathrm{~K}, \mathrm{LW}$. & dts & $\pi$ & s: & $2 \pi$ & 紋 & sxi & 48 & ASP \\
\hline$\$ z$ ata & 117: & $y: 4$ & $E F$ & 306 & tX & $Q R$ & 211 & 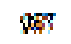 \\
\hline 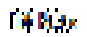 & 15 & b] & $+d$ & kta. & 15t & 谈 & 10 & ('s) \\
\hline
\end{tabular}

\section{Pengaturan Sinyal Pada Treble}

Dalam pengaturan treble tegangan sebesar $100 \mathrm{mV}$ dalam bentuk gelombang sinus diterapkan. Pengaturan langkah 3 sebesar $0 \mathrm{~dB}$ digunakan untuk kondisi masukan sinyal flat. Langkah ke-0 ampai langkah ke-7 dilakukan perubahan pada pengaturan treble ini. Hasil yang diperoleh tegangan tertinggi didapatkan pada frekuensi $16 \mathrm{kHz}$ dengan tegangan sebesar $990 \mathrm{mV}$, sedangkan tegangan terendah sebesar $30 \mathrm{mV}$ di dapatkan pada frekuensi $100 \mathrm{~Hz}$. Tabel 3 memperlihatkan tegangan tiap langkah pada pengaturan treble. Tegangan ini dalam skala $\mathrm{mV}$.

Tabel 2. Tegangan pengaturan treble.

\begin{tabular}{|c|c|c|c|c|c|c|c|c|}
\hline 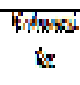 & $\begin{array}{c}\text { Low } 36 \\
6 / 4\end{array}$ & 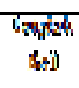 & 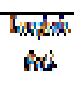 & 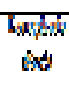 & 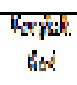 & 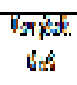 & $\begin{array}{c}T_{z} \times x_{5} \\
h_{n \rightarrow 6}\end{array}$ & $\begin{array}{c}\text { wash } \\
M x\end{array}$ \\
\hline 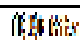 & 4 & की & d) & $\$$ & "滞 & 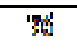 & 2 & $1 \%$ \\
\hline 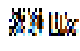 & I的 & {$[168$} & $i$ ib & 04 & l. & shl & $i 62$ & 湈 \\
\hline i) $\mathrm{kr} / \mathrm{kr}$ & $11 \mathrm{R}$ & t5 & $\left.\mathrm{W}_{1}\right\rangle$ & $\sqrt{6} \times$ & soses & siv & 4058 & $\mathbb{N}$ \\
\hline 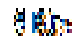 & 46 & 跑 & 制 & 被 & M & (96 & $49 \%$ & 滥心 \\
\hline 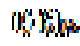 & 4 & 满 & $6 x$ & sis & 项 & 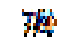 & 3 & by \\
\hline
\end{tabular}

\section{KESIMPULAN}

Dengan menggunakan mikrokontroller 8-bit ditambah dengan push button, dan multiplexer dapat menggantikan fungsi potensiometer pada tone control. Gain sebesar $6.02 \mathrm{~dB}$ merupakan penguatan tertinggi pada tone control ini. Peredaman dan penguatan tegangan dan frekuensi pada tone control ini dapat dilakukan dengan mudah dengan mengubah pengaturan langkah volume, bass dan treble.

\section{DAFTAR PUSTAKA}

[1] L. Arie and Nurhadi. "Aplikasi bell sekolah otomatis berbasis arduino dilengkapi dengan output suara", Jurnal Informatika, managemen dan komputer, vol. 10, no. 2, pp. 1-7, 2018.

[2] A. Mohamad."Pembuatan audio untuk mengolah sinyal input dari handphone", Jurnal Teknologi Terpadu Poltekba, vol.4, no 2, pp. 120-129, 2016.

[3] H. Rahmad."Penerapan audio amplifier stereo untuk beban bersama dan bergantian dengan menggunakan saklar ganda sebagai pengatur beban”, Jurnal Teknik Elektro, vol. 5, no. 2, pp. 96-101, 2013.

[4] H. Yanuar Richo and S. Edy. "Pengembangan media pembelajaran trainer audio equalizer pada standar kompetensi perekayasa sistem audiodi SMK Negeri 1 Beji-Pasuruan", Jurnal Pendidikan Teknik Elektro, vol.6, no.03, pp. 255-260, 2017.

[5] Beauty, D. Agung, and Julius. M. "Perancangan rangkaian terpadu penguat operasional untuk pengatur nada", Jurnal EECCIS, vol.3, no.2, pp. 17-22, 2009. 